\title{
Benign penile skin anomalies in children: a primer for pediatricians
}

\author{
Marco Castagnetti, Mike Leonard, Luis Guerra, Ciro Esposito, Marcello Cimador \\ Padua, Italy
}

Background: Abnormalities involving the skin coverage of the penis are difficult to define, but they can significantly alter penile appearance, and be a cause of parental concern.

Data sources: The present review was based on a nonsystematic search of the English language medical literature using a combination of key words including "penile skin anomalies" and the specific names of the different conditions.

Results: Conditions were addressed in the following order, those mainly affecting the prepuce (phimosis, balanitis xerotica obliterans, balanitis, paraphimosis), those which alter penile configuration (inconspicuous penis and penile torsion), and lastly focal lesions (cysts, nevi and vascular lesions). Most of these anomalies are congenital, have no or minimal influence on urinary function, and can be detected on clinical examination. Spontaneous improvement is possible. In the majority of cases undergoing surgery, the potential psychological implications of genital malformation on patient development are the main reason for treatment, and the age generally recommended for surgery is after 12 months of age.

Conclusion: This review provides the pediatrician with a handy tool to identify the most common penile skin anomalies, counsel parents adequately, make sensible and

\footnotetext{
Author Affiliations: Section of Pediatric Urology, Urology Unit, University Hospital of Padova, Padua, Italy (Castagnetti M); Department of Surgery, Division of Pediatric Urology, Children's Hospital of Eastern Ontario, University of Ottawa, Ottawa, ON, Canada (Leonard M, Guerra L); Department of Pediatrics, Federico II University of Naples, Italy (Esposito C); Section of Pediatric Urology and Pediatric Surgery Unit, Department for Mother \& Child Care and Urology, University of Palermo, Palermo, Italy (Cimador M)

Corresponding Author: Marco Castagnetti, MD, Section of Pediatric Urology, Urology Unit, Depatment of Oncological Sciences, University Hospital of Padova, Monob locco Ospedaliero, Via Giustiniani, 2, 35128, Padua, Italy (Tel: +39 049 8212737; Fax: +39 049 8212721; Email: marcocastagnetti@hotmail.com)

doi: $10.1007 / \mathrm{s} 12519-015-0015-5$

C)Children's Hospital, Zhejiang University School of Medicine, China and Springer-Verlag Berlin Heidelberg 2015. All rights reserved.
}

evidence based choices for management, and recognize complications or untoward outcomes in patients undergoing surgery.

World J Pediatr March 2015; Online First

\author{
Key words: balanitis xerotica obliterans; \\ foreskin; \\ penis; \\ phimosis
}

\section{Introduction}

$\mathrm{P}$ nile anomalies are quite common in children and are almost invariably a cause of concern for their parents. Some of them, such as hypospadias or epispadias are clearly of surgical interest and specific reviews exist regarding their management. ${ }^{[1-3]}$ Abnormalities involving the skin coverage of the penis can be more difficult to define. In most of these cases, there is minimal or no impact on urinary function, but penile appearance can be significantly altered. Pediatricians are often the frontline physicians facing the problem and play a key role in reassuring the parents or sending a prompt referral to a surgeon in order to determine the need for surgical repair. Moreover they are often involved in the postoperative follow-up of these patients.

Therefore, the present non-systematic review provides the pediatrician with a handy tool to identify the most common penile skin anomalies, provide adequate counselling to the parents, make sensible and evidence-based choices for management, and recognize complications or untoward outcomes in patients undergoing surgery.

\section{General principles}

No thorough classification exists of penile skin anomalies in children. In the present review, conditions affecting mainly the prepuce are addressed first, followed by those which alter penile configuration, leaving for last focal lesions such as cysts, nevi or vascular lesions. From a clinical point of view, most of these anomalies are congenital. Most of them have no 
or minimal influence on urinary function and are easy to detect on clinical examination. Spontaneous improvement is possible. In the majority of cases undergoing surgery, the potential psychological implications of genital malformation on patient development are the main reason for treatment. In asymptomatic infants where spontaneous improvement cannot be anticipated, the age generally recommended for cosmetic genital surgery is between 6 and 18 months of age. ${ }^{[4]}$

\section{Conditions affecting mainly the prepuce Phimosis}

Phimosis is by far the most common penile skin anomaly in children (Fig. 1A). However, it is seldom pathological and has great potential for spontaneous improvement. Consistently, the prepuce is unretractable in almost $100 \%$ of infants vs. less than $5 \%$ of children approaching puberty. ${ }^{[5,6]}$ The reasons for improvement are as follows: 1) The prepuce is sensitive to androgens and the preputial outlet becomes wider once testosterone production starts; 2) In all neonates the skin is fused to the glans (balano-preputial adhesions) and the skin detaches as the latter produces a substance known as smegma, that accumulates between the skin and glans. The accumulating smegma can form "white cysts" under the skin that often prompt surgical consultation, but in fact do not need any treatment.

Given the natural history of phimosis in children, unless parents choose neonatal circumcision, ${ }^{[7]}$ only patients symptomatic, particularly those with recurrent local infections, should undergo surgery before puberty in the absence of foreskin abnormalities on physical examination (see below). In symptomatic patients, non-surgical treatment can still be offered in the form of a course of 4 to 8 weeks with 1 to 2 applications per day of topical steroids. ${ }^{[8-10]}$ Of note, it is controversial whether local steroids are more effective than preputial manipulation and stretching
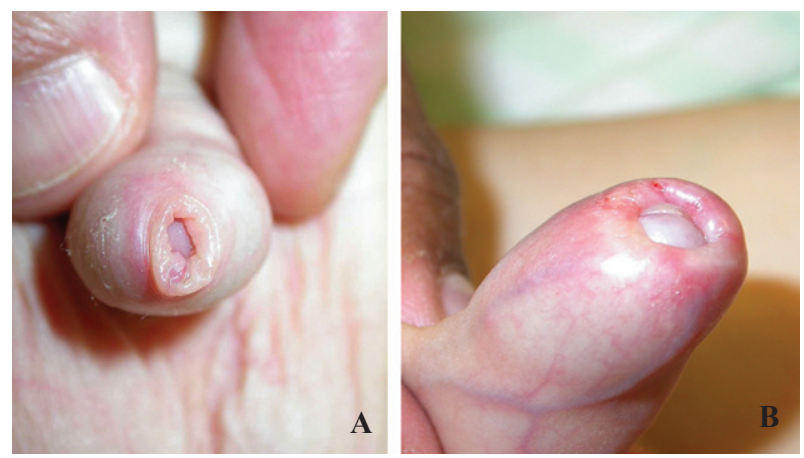

Fig. 1. A: Physiological phimosis; B: Phimosis owing to balanitis xerotica obliterans. alone. ${ }^{[9]}$ The effect of corticosteroids can be transient,,${ }^{[9]}$ but even a transient improvement might be considered predictive of spontaneous resolution at puberty. In patients experiencing recurrent symptoms despite local steroids, circumcision is the standard treatment. If the patient or the parents wish the prepuce to be preserved, preputioplasty techniques involving a dorsal incision widening the preputial ring are an option, although many surgeons consider the cosmetic results of these procedures unacceptable ${ }^{[11,12]}$ Circumcision can be associated with severe complications, such as glanular amputation or urethral fistula formation, if the procedure is performed by physicians not properly trained ${ }^{[13]}$ In the hospital setting, complications after elective circumcision are reportedly below $1 \%$. Acute complications are usually minor and most commonly involve bleeding, infection, or an imperfect cosmetic outcome. Late complications include trapped penis, skin bridges, and meatal stenosis. ${ }^{[14]}$

\section{Balanitis xerotica obliterans (BXO)}

Physiological phimosis should be differentiated from that due to BXO. The latter is a chronic progressive dermatitis of unknown etiology that occurs on the penile skin. In fact, BXO is a variant of lichen sclerosus et atrophicus confined to the male genitalia, in most cases only the prepuce, but in some the external urethral meatus and urethra. The incidence of the condition is unknown, but most authors agree it is increasing and many cases of phimosis undergoing non-elective circumcision in childhood might be in fact have undiagnosed $\mathrm{BXO} \cdot{ }^{[15]}$ Consistently, it was reported that approximately half of prepuces obtained from nonelective circumcisions were consistent with a diagnosis of BXO ${ }^{[16,17]} \mathrm{BXO}$ is diagnosed by histological features including hyperkeratosis and hyperplasia of the squamous mucosa along with homogenous collagen deposition in the upper dermis. ${ }^{[15]}$ Clinically, the condition can be suspected in the presence of a white, sclerotic, distal preputial ring (Fig. 1B). Sclerotic lesions might also involve the glans. If the inflammatory process involves the external urethral meatus or urethra, meatal stenosis or urethral strictures can ensue. Most of the patients are asymptomatic. Progressive preputial tightening is the most common complaint. Nonspecific voiding symptoms can be present, particularly if there is involvement of the external meatus or urethra. ${ }^{[18]}$

In terms of treatment, circumcision alone is generally curative. Meatotomy or meatoplasty might be required in cases of meatal stenosis, whereas rare cases of urethral stricture might require substitution urethroplasty with oral mucosa. ${ }^{[18,19]}$ Adjuvant treatments with corticosteroids have also been proposed 
preoperatively, intraoperatively, or postoperatively, but the actual role of such an adjunctive treatment is unknown. ${ }^{[18]}$ Surgery for BXO can be associated with quite a high complication rate. Phimosis can recur after circumcision and the disease can progress leading to meatal stenosis or urethral stricture.

\section{Penile infections and inflammation}

Normal penile skin is susceptible to infections and inflammation. Specific infections and sexually transmitted disease are beyond the scope of the present review. Non-specific infections are most commonly caused by gram-positive organisms (Staphylococcus Pyogenes and Staphylococcus Aureus), which are saprophytes of the skin. However, the causative organism is seldom identified, as swab cultures are generally not obtained. The infection causes a collection of debris or pus under the foreskin that presents with swelling, erythema and inflammation. This is called balanitis or balanoposthitis. When the bacteria find skin or mucosal breakdown, they gain access to the subcutaneous tissue, resulting in diffuse cellulitis of the whole penis (Fig. 2). In more severe cases, skin erythema can be accompanied by pain and fever. Treatment of balanoposthitis generally includes sitz baths and local antibiotic creams. ${ }^{[20]}$ In cases of penile cellulitis or systemic symptoms, oral broadspectrum antibiotics should be administered. Short-term bladder catheterization can be required in cases of acute urinary retention. Surgical procedures, such as incision and drainage, are almost never required, but recurrent infections can cause local scarring and phimosis requiring eventual circumcision.

Other possible etiologies should be taken into consideration while assessing patients presenting with penile swelling, erythema, and inflammation caused by trauma, hair coil penile strangulation syndrome, animal attack, insect bite, bicycle accident, zipper injury and electrical injury. ${ }^{[21-26]}$ History and physical examination do not always help in ruling out these causes. Insect bite is often not witnessed by the family and the bite site cannot be identified, whereas skin swelling can cover the strangulation point from a hair tourniquet.

\section{Paraphimosis}

Paraphimosis is defined by acute swelling and inflammation of the distal penis and glans caused by a constriction force acting like a tourniquet. The most common factors associated with paraphimosis are forced retraction of a phimotic foreskin that is left behind the glans, or circular scar of the residual prepuce post circumcision. A hair tourniquet can however produce the same effect. Paraphimosis is a medical emergency and most cases are reduced in the emergency room with the use of local anesthetics, oral morphine or intravenous injection sedation depending on the age of the patient. The maneuver used for reduction of an uncomplicated paraphimosis is performed by first squeezing the glans gently to reduce its volume and then, with the help of the index and middle fingers, the thumb is used to slowly push the glans proximally through the phimotic ring. Other substances or maneuvers have been used to help reduce glans swelling. They include sugar, ${ }^{[27]}$ mannitolsoaked gauze,${ }^{[28]}$ hyaluronidase ${ }^{[29]}$ puncture of the prepuce with a small gauge needle, ${ }^{[30]}$ and an ice pack. ${ }^{[31]}$ If conservative maneuvers are not successful, dorsal slit may be required. In cases associated with a hair tourniquet, the hair needs to be removed or cut. In cases of preputial maceration without infection, circumcision removing the damaged skin may provide an adequate result. Although most patients with paraphimosis will look for medical attention due to pain and inability to void, rare cases of late presentation may lead to glanular ischemia. ${ }^{[32]}$

\section{Hypospadiac prepuce}

This term defines a prepuce deficient ventrally and with a full dorsal attachment. The condition is usually associated with distal hypospadias, but can also be isolated (Fig. 3). Under these circumstances, either circumcision

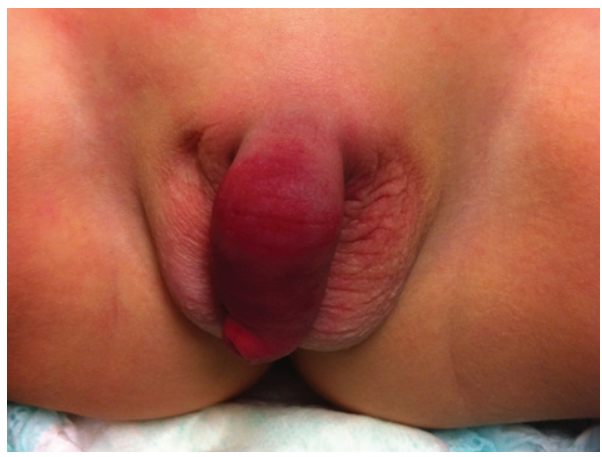

Fig. 2. Penile cellulitis.
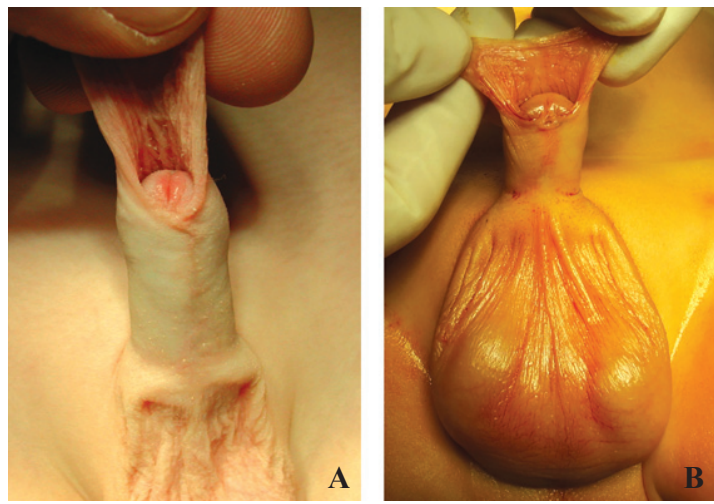

Fig. 3. Hypospadiac prepuce in a patient without hypospadias (A) and a patient with glanular hypospadias (B). 
or preputial reconstruction can be offered. The choice between the procedures depends on several factors including parental preferences and feasibility. In patients with glanular hypospadias, preputial reconstruction can be an easy way to conceal the malformation while avoiding urethral surgery. ${ }^{[33]}$ Moreover, the prepuce is erogenous tissue and its preservation might be important. ${ }^{[34]}$ The feasibility of preputial reconstruction can only be determined at the time of surgery. The two major issues that should be considered are whether the prepuce is required to create a barrier layer to cover the urethroplasty, and that it is wide enough to avoid secondary phimosis. ${ }^{[34,35]}$ The major complications specific to preputial reconstruction include dehiscence of the suture line and secondary phimosis. Series on preputial reconstruction in hypospadias patients show that these complications occur in $2 \%-20 \%$ of cases. ${ }^{[36,37]}$

\section{Conditions altering penile configuration Inconspicuous/concealed penis}

An inconspicuous penis is a condition where the penis appears to be very short. Micropenis refers to an inconspicuous penis because of a short penile shaft. This is due to prenatal endocrinopathy and is exceedingly rare ${ }^{[38]} \mathrm{A}$ concealed penis is a condition where the penile shaft size is normal, but the penis is concealed because of abnormal skin coverage. Maizels et $\mathrm{al}^{[39]}$ described three major variants of concealed penis including the buried penis, the webbed penis, and the trapped penis. Next to these, megaprepuce has more recently been added. ${ }^{[40]}$

\section{Buried penis}

A buried penis refers to a normal-sized penis buried in prepubic tissue. A normal penis can be buried by large scrotal masses, such as hernias and/or hydroceles or by the presence of suprapubic fat in obese patients (Fig. 4). The former variants require treatment of the underlying

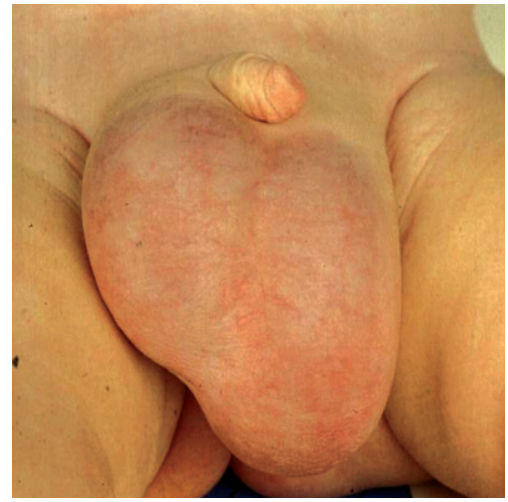

Fig. 4. Bilateral hydrocele mimicking a buried penis in an infant. conditions, and the latter appropriate dietary advice and physical activity. The prepubic fat can reduce in volume dramatically as the child learns to walk. Some surgeons recommend that any surgery is deferred at least until the child is 3 years old. ${ }^{[41]}$ Moreover, since prepubic fat is sensitive to androgens, penile appearance can improve spontaneously as the child approaches puberty. ${ }^{[42,43]}$ Alternatively, a true buried penis is due to superficial fascial laxity with lack of skin attachment to the shaft and subsequent absence of a peno-pubic and penoscrotal angle (Fig. 5A).

\section{Megaprepuce}

Megaprepuce is characterized by a penis with a wide dome-shaped base that exhibits hemispheric ballooning during micturition (Fig. 5B). It is indeed a variant of buried penis where there is also a large redundancy of the inner preputial layer. It has been widely debated whether such skin excess is congenital or acquired because of progressive stretching of the inner preputial mucosa during micturition in a phimotic prepuce. ${ }^{[40]}$ However, some megaprepuces do not have associated phimosis. ${ }^{[44]}$

\section{Webbed penis}

This is normally the result of abnormal dartos bands anchoring the penile skin on the surface of the scrotum. This results in the obliteration of ventral penoscrotal angle and resultant appearance of a short penis (Fig. 5C). It has also been referred to as penis palmatus. ${ }^{[45]}$ It is considered to be a form of aberrant preputial formation leading to varying visualization of the ventral aspect of the penis. ${ }^{[46]}$

\section{Trapped penis}

This is an acquired form of concealed penis, where the penile skin after circumcision has formed a
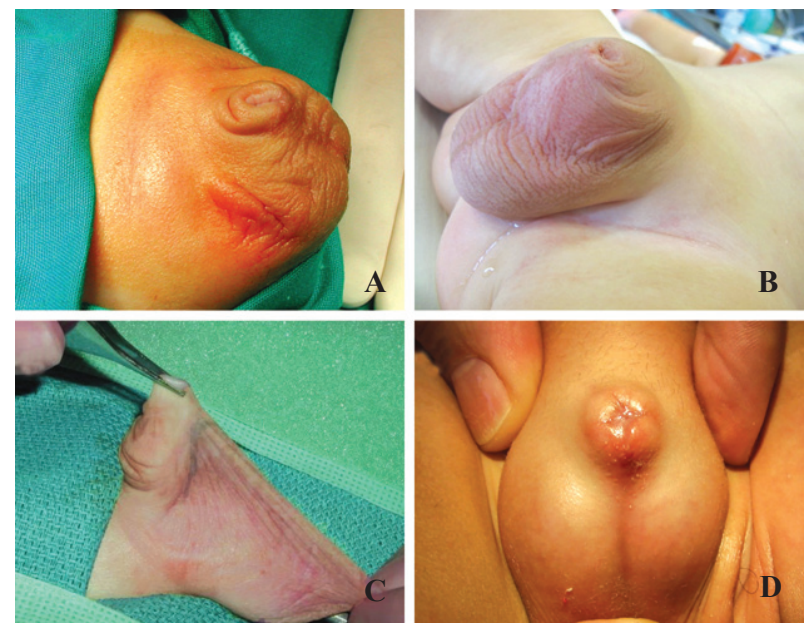

Fig. 5. Variants of inconspicuous penis. A: Buried penis; B: Megaprepuce; C: Webbed penis; D: Trapped penis.

World J Pediatr, Online First, March $2015 \cdot$ www.wjpch.com 
circumferential scar distal to or at the level of the glans, and traps the penis within the scar embedded in the prepubic fat or scrotum (Fig. 5D). This can happen with overexuberant circumcision, or circumcision in a child with a buried or webbed penis, where the skin laxity was not addressed. It can also happen when circumcision was performed in a child with scrotal swelling, where in the early postoperative period the scrotal skin develops adhesions with the dorsal skin because of its redundancy. A study ${ }^{[47]}$ reported that $2.9 \%$ of neonatal circumcisions end up with secondary phimosis with a trapped penis.

\section{Clinical assessment of inconspicuous penis}

Clinically, voiding symptoms are exceptional in patients with buried, webbed, and trapped penis. In patients with megaprepuce, the dilated foreskin can balloon during micturition, thereby causing patient discomfort or a weak stream. In most infants, however, the problem can temporarily be addressed by instructing the parents how to milk the prepuce to evacuate the contained urine. It is noteworthy that the presence of urine under the prepuce in patients with megaprepuce can often cause positive urine cultures, since during micturition the urine flushes the interior of the prepuce and is almost invariably contaminated by the organisms normally present therein. Therefore, the physician should be cautious about recommending courses of antibiotic treatment or continuous antibiotic prophylaxis in these patients.

On physical examination, the most important thing is to differentiate these skin anomalies from the presence of a micropenis. In the former, the penile shaft is normal and it is the excessive redundancy or abnormal anchoring of the surrounding tissues that makes the penis look relatively diminutive. This can often be
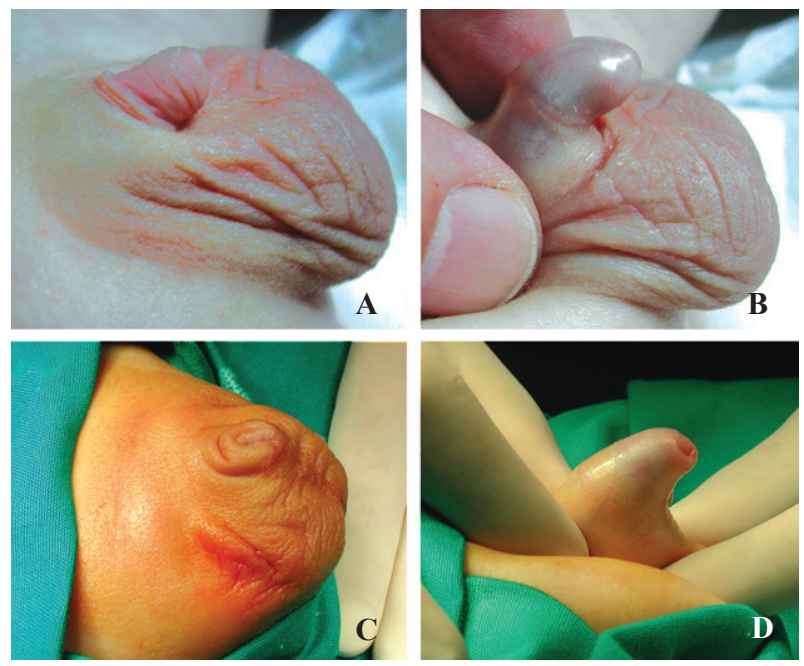

Fig. 6. A\&B: Micropenis; C\&D: Buried penis.

World J Pediatr, Online First, March 2015 - www.wjpch.com demonstrated on physical examination, as by pushing down the skin the corpora cavernosa can be palpated and the actual length of the penis appreciated (Fig. 6). The differential diagnosis between a buried penis due to pubic adiposity and one due to lack of skin attachments cannot be easily made. Borsellino et al ${ }^{[43]}$ suggested that the presence of a circumferential groove at the base of the penis indicates normal peno-pubic and peno-scrotal angles.

\section{Principles of management}

It is essential that patients with a buried penis or megaprepuce are not circumcised, as the prepuce is required to cover the penile shaft eventually. ${ }^{[48,49]}$ Circumcision can result in a trapped penis that may require the use of a free skin graft afterwards (Fig. 5D). All the techniques for repair involve the general principles of skin tapering and fixation to recreate a cylindrical penis with a peno-pubic and peno-scrotal angle. ${ }^{[43,49]}$ Complications are rare, but recurrence of the condition is possible. Skin redundancy owing to inadequate trimming or residual penile torsion owing to asymmetry in skin fixation may also occur.

\section{Penile torsion}

Penile torsion is defined as rotation of the longitudinal axis of the penis (penile shaft) and glans. Torsion is more commonly counter-clockwise. It may present in isolation or be associated with hypospadias or penile curvature ${ }^{[50]}$ The malformation is considered common, but the actual incidence is not known, since many cases are mild and do not require treatment owing to low morbidity and minimal impact on sexual or urinary function. ${ }^{[51]} \mathrm{A}$ study involving a large number of adults with this condition seen in an infertility/sexual dysfunction clinic found that $12 \%$ had penile torsion but only $2 \%$ of them required surgery, primarily for cosmetic reasons. ${ }^{[52]}$ The etiology of the condition is unclear, but it has been suggested that it may be related to abnormal skin and dartos fascial attachments, ${ }^{[33,54]}$ or to some degree of hypoplasia of the corpora cavernosa associated with a fibrous band that attaches the corpora tightly to the pubic periosteum. ${ }^{[55]}$ Children are usually asymptomatic. Although the degree of torsion (measured as the angle between a line passing through the urethral meatus and the midline of the scrotum) justifying correction is still controversial, ${ }^{[56]}$ it is generally agreed that rotations less than 60 degrees do not merit repair. ${ }^{[56-61]}$ Children with more severe or symptomatic penile torsion should be referred to a pediatric urologist, and the parents and patients should be counselled about this very benign condition that has limited surgical options and variable results. $^{[56-61]}$ 


\section{Scrotal anomalies: bifid scrotum, penoscrotal transposition}

Peno-scrotal transposition is an anomaly of the genitalia where there is a partial or complete positional exchange between the penis and scrotum (Fig. 7). The etiology of the condition remains uncertain. Embryologically, peno-scrotal transposition results from a defect in the process of caudal migration or fusion of labio-scrotal swellings that originate one on each side of the fetal phallus. Glenn and Anderson ${ }^{[62]}$ classified peno-scrotal transposition into 4 categories with progressive severity including bifid scrotum, incomplete or partial penoscrotal transposition, complete penoscrotal transposition or pre-penile scrotum, and ectopic scrotum. Of note, the webbed penis and the high insertion of the scrotum seen in a few cases of hypospadias might be considered variants of peno-scrotal transposition. The condition is rare. The largest series reported so far comprises 53 cases treated over a 25 -year period at the Mayo Clinic. ${ }^{[63]}$ The malformation is seldom isolated and is more commonly seen in patients with severe variants of hypospadias ( $80 \%$ in the series from the Mayo Clinic). Up to $100 \%$ of cases were found to have associated renal defects, and also musculoskeletal, gastrointestinal, cardiac, and central nervous system associated anomalies have been
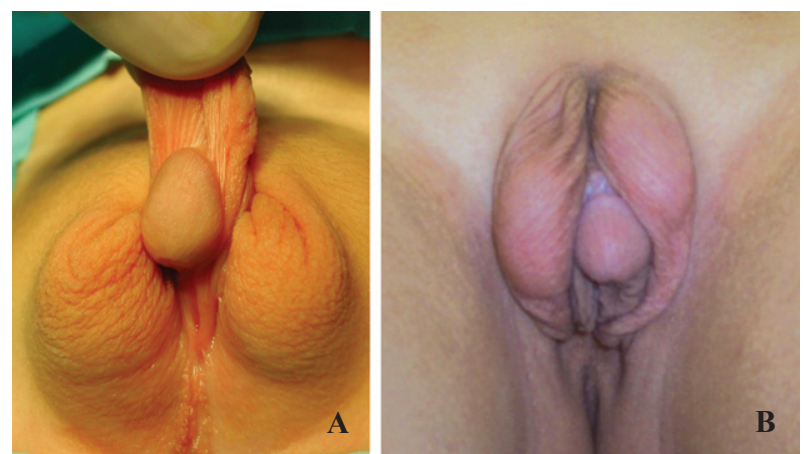

Fig. 7. Penoscrotal transposition. A: Bifid scrotum; B: Complete penoscrotal transposition.
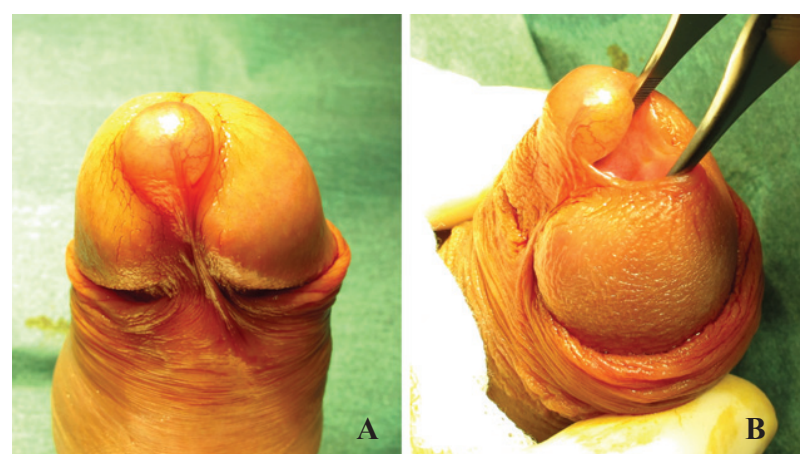

Fig. 8. This is a variant of penile cysts. A\&B: Parameatal cyst. reported. Mild variants are generally considered not to require surgery. Of note, surgery for the correction of peno-scrotal transposition is fraught with a complication rate as high as $70 \% .{ }^{[63]}$

\section{Focal lesions}

\section{Penile/scrotal cysts}

Cysts can arise at any level in the penis or scrotum. They can be congenital or acquired. Acquired cysts are generally inclusion cysts after penile surgery such as hypospadias repair or circumcision. ${ }^{[64,65]}$ Congenital cysts are usually epidermoid and typically originate from the median raphe at any level from the urethral meatus (in which case they are termed parameatal cysts, Fig. 8$)^{[66]}$ to the base of the scrotum. ${ }^{[67]}$ They arise from epithelial rests incidental to incomplete closure of urethral or genital folds, or from split off growths of embryological epithelium after primary closure of the folds. The cysts can extend to the pelvis, but have no communication with the urethra. ${ }^{[67]}$ Cysts palpable under a non-retractable prepuce should be differentiated from smegma cysts (see paragraph on phimosis). Scrotal cysts should be differentiated from other possible causes of scrotal swelling, primarily testicular tumors. ${ }^{[68]}$

Excision of penile and scrotal cysts is generally curative. Recurrence is possible in theory, but has never been reported. Cosmetic results are generally excellent.

\section{Penile nevi}

Congenital melanocytic nevus is the most common lesion in penile nevi. In general, it has an incidence of one in 100 neonates and it may be present anywhere on the skin of the body including the glans and penile shaft. Genital locations of such nevi are unusual. They are typically brown or black skin moles present at birth, or they may develop in the first year of life. Located on the penis, they are usually small, do not cause symptoms, and are treated by excisional biopsy. The pathological classification is based on the location of the melanocytes: dermal (dermis), junctional (dermalepidermal junction) and compound (involving both dermis and dermal-epidermal junction) ${ }^{[69]}$ There is a small possibility of malignant transformation of large melanocytic nevi, ${ }^{[70]}$ and surgical excision should be curative. ${ }^{[71]}$

\section{Penile vascular anomalies and neurogenic lesions}

Vascular anomalies involving the male genitalia can cause considerable distress, adversely impact a patient's self-image, inflict pain, and alter function. In a few cases they involve the underlying structures, such as the urethra. ${ }^{[72]}$ In a large series of vascular anomalies,

World J Pediatr, Online First, March $2015 \cdot$ www.wjpch.com 
genital lesions accounted for $3 \%$ of cases. ${ }^{[73]}$ Treatment was required in $70 \%$ of these cases and there was a high rate of persistence or recurrence during followup. ${ }^{[73]}$ Neurogenic lesions are exceedingly rare and the literature is limited to a few case reports. ${ }^{[69]}$ Treatment should be individualized and left to the specialist. ${ }^{[99]}$

\section{Conclusions}

Penile skin anomalies include a wide range of conditions. These anomalies can be congenital or acquired. In most cases they are isolated, but penoscrotal transposition is often seen in syndromic patients. Some of them do not cause any clinical problems, and can even improve spontaneously such most penile torsions or neonatal/physiological phimosis. However, a minority, such as BXO, require timely referral for surgical advice. Paraphimosis is an emergency, and delayed treatment can cause severe sequelae. In a few instances, such as the different forms of concealed penis, surgery may be considered to improve penile appearance. Under these circumstances, parental wishes should be taken into account.

\section{Funding: None.}

Ethical approval: Not required.

Competing interest: None.

Contributors: Castagnetti $\mathrm{M}$ proposed the study and wrote the first draft. Leonard M and Guerra L provided advice on medical aspects. All authors contributed to the intellectual content and to further drafts, and approved the final version. Castagnetti $M$ is the guarantor.

\section{References}

1 Borer JG, Retik AB. Current trends in hypospadias repair. Urol Clin North Am 1999;26:15-37.

2 Castagnetti M, El-Ghoneimi A. Surgical management of primary severe hypospadias in children: systematic 20 -year review. J Urol 2010;184:1469-1474.

3 Ebert AK, Reutter H, Ludwig M, Rösch WH. The exstrophyepispadias complex. Orphanet J Rare Dis 2009;4:23.

4 American Academy of Pediatrics. Timing of elective surgery on the genitalia of male children with particular reference to the risks, benefits, and psychological effects of surgery and anesthesia. Pediatrics 1996;97:590-594.

5 Yang C, Liu X, Wei GH. Foreskin development in 10421 Chinese boys aged 0-18 years. World J Pediatr 2009;5:312-315.

6 Hsieh TF, Chang CH, Chang SS. Foreskin development before adolescence in 2149 schoolboys. Int J Urol 2006;13:968-970.

7 American Academy of Pediatrics Task Force on Circumcision. Male circumcision. Pediatrics 2012;130:e756-e785.

8 Yang SS, Tsai YC, Wu CC, Liu SP, Wang CC. Highly potent and moderately potent topical steroids are effective in treating phimosis: a prospective randomized study. J Urol
2005;173:1361-1363.

9 Letendre J, Barrieras D, Franc-Guimond J, Abdo A, Houle AM. Topical triamcinolone for persistent phimosis. J Urol 2009;182:1759-1763.

10 Kuehhas FE, Miernik A, Sevcenco S, Tosev G, Weibl P, Schoenthaler M, et al. Predictive power of objectivation of phimosis grade on outcomes of topical $0.1 \%$ betamethasone treatment of phimosis. Urology 2012;80:412-416.

11 Dessanti A, Ginesu G, Iannuccelli M, Balata A. Phimosis Preputial plasty using transversal widening on the dorsal side with EMLA local anesthetic cream. J Pediatr Surg 2005;40:713715.

12 Nieuwenhuijs JL, Dik P, Klijn AJ, de Jong TP. Y-V plasty of the foreskin as an alternative to circumcision for surgical treatment of phimosis during childhood. J Pediatr Urol 2007;3:45-47.

13 Ceylan K, Burhan K, Yilmaz Y, Can S, Kuş A, Mustafa G. Severe complications of circumcision: an analysis of 48 cases. J Pediatr Urol 2007;3:32-35.

14 Cathcart P, Nuttall M, van der Meulen J, Emberton M, Kenny SE. Trends in paediatric circumcision and its complications in England between 1997 and 2003. Br J Surg 2006;93:885-890.

15 Kiss A, Király L, Kutasy B, Merksz M. High incidence of balanitis xerotica obliterans in boys with phimosis: prospective 10-year study. Pediatr Dermatol 2005;22:305-308.

16 Bochove-Overgaauw DM, Gelders W, De Vylder AM. Routine biopsies in pediatric circumcision: (non) sense? J Pediatr Urol 2009;5:178-180.

17 Jayakumar S, Antao B, Bevington O, Furness P, Ninan GK. Balanitis xerotica obliterans in children and its incidence under the age of 5 years. J Pediatr Urol 2012;8:272-275.

18 Celis S, Reed F, Murphy F, Adams S, Gillick J, Abdelhafeez AH, et al. Balanitis xerotica obliterans in children and adolescents: a literature review and clinical series. J Pediatr Urol 2014;10:3439.

19 Gargollo PC, Kozakewich HP, Bauer SB, Borer JG, Peters CA, Retik AB, et al. Balanitis xerotica obliterans in boys. J Urol 2005;174:1409-1412.

20 Schwartz RH, Rushton HG. Acute balanoposthitis in young boys. Pediatr Infect Dis J 1996;15:176-177.

21 Smith GA, Sharma V, Knapp JF, Shields BJ. The summer penile syndrome: seasonal acute hypersensitivity reaction caused by chigger biteson the penis. Pediatr Emerg Care 1998;14:116-118.

22 Gomes CM, Ribeiro-Filho L, Giron AM, Mitre AI, Figueira ER, Arap S. Genital trauma due to animal bites. J Urol 2001;165:8083.

23 El-Bahnasawy MS, El-Sherbiny MT. Paediatric penile trauma. BJU Int 2002;90:92-96.

24 Badawy H, Soliman A, Ouf A, Hammad A, Orabi S, Hanno A. Progressive hair coil penile tourniquet syndrome: multicenter experience with 25 cases. J Pediatr Surg 2010;45:1514-1518.

25 Tiengo C, Castagnetti M, Garolla A, Rigamonti W, Foresta C, Azzena B. High-voltage electrical burn of the genitalia, perineum, and upper extremities: the importance of a multidisciplinary approach. J Burn Care Res 2011;32:e168-e171.

26 Djordjevic ML, Bumbasirevic MZ, Krstic Z, Bizic MR, Stojanovic BZ, Miocinovic R, et al. Severe penile injuries in children and adolescents: reconstruction modalities and outcomes. Urology 2014;83:465-470.

27 Mackway-Jones K, Teece S. Best evidence topic reports. Ice, pins, or sugar to reduce paraphimosis. Emerg Med J 2004;21:7778.

28 Anand A, Kapoor S. Mannitol for paraphimosis reduction. Urol 
Int 2013;90:106-108.

29 DeVries CR, Miller AK, Packer MG. Reduction of paraphimosis with hyaluronidase. Urology 1996;48:464-465.

30 Kumar V, Javle P. Modified puncture technique for reduction of paraphymosis. Ann R Coll Surg Engl 2001;83:126-127.

31 Choe JM. Paraphimosis: current treatment options. Am Fam Physician 2000;62:2623-2626, 2628.

32 Raman SR, Kate V, Ananthakrishnan N. Coital paraphimosis causing penile necrosis. Emerg Med J 2008;25:454.

33 Zimmermann EF, Woodward MN. Isolated preputial reconstruction in distal hypospadias. J Pediatr Urol 2014;10:399. e1-399.e2.

34 Castagnetti M. Commentary to "Foreskin retractility following hypospadias repair with preputioplasty--medium term outcomes". J Pediatr Urol 2013;9:1209.

35 Kallampallil J, Hennayake S. Foreskin retractility following hypospadias repair with preputioplasty--medium term outcomes. J Pediatr Urol 2013;9:1204-1209.

36 Gray J, Boston VE. Glanular reconstruction and preputioplasty repair for distal hypospadias: a unique day casemethod to avoid urethral stenting and preserve the prepuce. BJU Int 2003;91:268270.

37 Klijn AJ, Dik P, de Jong TP. Results of preputial reconstruction in 77 boys with distal hypospadias. J Urol 2001;165:1255-1257.

38 Hatipoğlu N, Kurtoğlu S. Micropenis: etiology, diagnosis and treatment approaches. J Clin Res Pediatr Endocrinol 2013;5:217223.

39 Maizels M, Zaontz M, Donovan J, Bushnick PN, Firlit CF. Surgical correction of the buried penis: description of a classification system and a technique tocorrect the disorder. J Urol 1986;136:268-271.

40 O'Brien A, Shapiro AM, Frank JD. Phimosis or congenital megaprepuce? Br J Urol 1994;73:719-720.

41 Eroğlu E, Bastian OW, Ozkan HC, Yorukalp OE, Goksel AK. Buried penis after newborn circumcision. J Urol 2009;181:18411843.

42 Crawford BS. Buried penis. Br J Plast Surg 1977;30:96-99.

43 Borsellino A, Spagnoli A, Vallasciani S, Martini L, Ferro F. Surgical approach to concealed penis: technical refinements and outcome. Urology 2007;69:1195-1198.

44 Summerton DJ, McNally J, Denny AJ, Malone PS. Congenital megaprepuce: an emerging condition--how to recognize and treat it. BJU Int 2000;86:519-522.

45 Masih BK, Brosman SA. Webbed penis. J Urol 1974;111:690692.

46 Perlmutter AD, Chamberlain JW. Webbed penis without chordee. J Urol 1972;107:320-321.

47 Blalock HJ, Vemulakonda V, Ritchey ML, Ribbeck M. Outpatient management of phimosis following newborn circumcision. J Urol 2003;169:2332-2334.

48 Sivakumar B, Brown AA, Kangesu L. Circumcision in "buried penis"--a cautionary tale. Ann R Coll Surg Engl 2004;86:35-37.

49 Hadidi AT. Buried penis: classification surgical approach. J Pediatr Surg 2014;49:374-379.

50 Fisher PC, Park JM. Penile torsion repair using dorsal dartos flap rotation. J Urol 2004;171:1903-1904.

51 Sarkis PE, Sadasivam M. Incidence and predictive factors of isolated neonatal penile glanular torsion. J Pediatr Urol 2007;3:495-499.

52 Shaeer $\mathrm{O}$. Torsion of the penis in adults: prevalence and surgical correction. J Sex Med 2008;5:735-739.
53 Culp OS. Struggles and triumphs with hypospadias and associated anomalies: review of 400 cases. J Urol 1966;96:339351 .

54 Pomerantz P, Hanna M, Levitt S, Kogan S. Isolated torsion of penis. Report of 6 cases. Urology 1978;1:37-39.

55 Snodgrass W. Editorial comment. J Urol 2009;182:290.

56 Zhou L, Mei H, Hwang AH, Xie HW, Hardy BE. Penile torsion repair by suturing tunica albuginea to the pubic periosteum. J Pediatr Surg 2006;41:e7-e9.

57 Snow BW. Penile torsion correction by diagonal corporal plication sutures. Int Braz J Urol 2009;35:56-59.

58 Fisher PC, Park JM. Penile torsion repair using dorsal dartos flap rotation. J Urol 2004;171:1903-1904.

59 Bauer R, Kogan BA. Modern technique for penile torsion repair. J Urol 2009;182:286-291.

60 Bhat A, Bhat MP, Saxena G. Correction of penile torsion by mobilization of urethral plate and urethra. J Pediatr Urol 2009;5:451-457.

61 Aldaqadossi HA, Elgamal SA, Seif Elnasr MK. Dorsal dartos flap rotation versus suturing tunica albuginea to the pubic periosteum for correction of penile torsion: a prospective randomized study. J Pediatr Urol 2013;9:643-647.

62 Glenn JF, Anderson EE. Surgical correction of incomplete penoscrotal transposition. J Urol 1973;110:603-605.

63 Pinke LA, Rathbun SR, Husmann DA, Kramer SA. Penoscrotal transposition: review of 53 patients. J Urol 2001;166:1865-1868.

64 Amukele SA, Stock JA, Hanna MK. Management and outcome of complex hypospadias repairs. J Urol 2005;174:1540-1542.

65 Tempark T, Wu T, Singer C, Shwayder T. Dermatological complications of circumcision: lesson learned from cases in a pediatric dermatology practice. Pediatr Dermatol 2013;30:519528.

66 Willis HL, Snow BW, Cartwright PC, Wallis MC, Oottamasathien S, deVries C. Parameatal urethral cysts in prepubertal males. J Urol 2011;185:1042-1045.

67 Canali R, Angelini L, Castagnetti M, Zhapa E, Rigamonti W. Scrotal dermoid extending to the posterior urethra through a corpus cavernosum in a child. J Pediatr Surg 2012;47:16181621.

68 Yuan X, Wei G, Lin T, He D, Li X. Uncommon pediatric painless scrotal masses: a puzzle of pediatricians and urologists. Int Urol Nephrol 2010;42:979-984.

69 Papali AC, Alpert SA, Edmondson JD, Maizels M, Yerkes E, Hagerty $\mathrm{J}$, et al. A review of pediatric glans malformations: a handy clinical reference. J Urol 2008;180:1737-1742.

70 Bittencourt FV, Marghoob AA, Kopf AW, Koenig KL, Bart RS. Large congenital melanocytic nevi and the risk for development of malignant melanoma and neurocutaneous melanocytosis. Pediatrics 2000;106:736-741.

71 Price HN, Schaffer JV. Congenital melanocytic nevi-when to worry and how to treat: Facts and controversies. Clin Dermatol 2010;28:293-302.

72 Leavitt DA, Hottinger DG, Reed RC, Shukla AR. A case series of genital vascular anomalies in children and their management: lessons learned. Urology 2012;80:914-918.

73 Kulungowski AM, Schook CC, Alomari AI, Vogel AM, Mulliken JB, Fishman SJ. Vascular anomalies of the male genitalia. J Pediatr Surg 2011;46:1214-1221. 